\title{
Teaching and Learning Sociolinguistic Competence: Teachers' Critical Perceptions
}

\author{
Enisa Mede ${ }^{*}$ \\ Bahçeşehir University, Department of English Language Teaching, Istanbul, \\ Turkey
}

Kenan Dikilitaş

Hasan Kalyoncu University, Department of English Language Teaching, Gaziantep, Turkey

\begin{tabular}{l}
\hline Article history \\
\hline Received: \\
02.09 .2015
\end{tabular}

Received in revised form: 18.10.2015

Accepted:

14.10.2015

Key words:

Communicative competence; sociolinguistic competence; teacher perceptions, English as a foreign language (EFL), teaching and learning curricula.
Sociolinguistic competence has been an integral part of communicative competence in that it includes learning pragmatic and sociolinguistic knowledge about how to use language linguistically and socially appropriately. However, a number of studies highlight the lack of such communicative skills among EFL learners regardless of their proficiency level of linguistic knowledge. More specially, learners may not be able to develop socio-pragmatic knowledge of language as much as grammatical knowledge of the language being learnt. Informed by this critical inconsistency and learning challenge, this study reports the perceptions of English teachers about the development of sociolinguistic competence in language classrooms. The purpose is to explore their perceptions about learners' as well as the non-native EFL teachers' knowledge of sociolinguistic competence along with any difficulty they may face with the integration of this particular competence in their classroom practice. Both native $(n=35)$ and non-native $(n=35)$ English teachers were administered a questionnaire and were asked to submit written reports revealing their perceptions underpinning the knowledge and practice of sociolinguistic competence as part of communicative competence. The results revealed that the development of sociolinguistic rules can guide learners in the choice of appropriate forms which should be closely integrated in language teaching and learning curricula.

\section{Introduction}

In today's increasingly globalized world, the ability to express oneself in a second or foreign language has become a vital skill (Mizne, 2007). An L2 speaker is considered fluent if he or she is able to use the language in a range of situational contexts such as talking in a formal meeting, or making telephone calls. However, no matter how long the L2 language learner is exposed to the target language, he or she might still have difficulty in expressing that language to a native speaker in different social settings. In other words, the language

\footnotetext{
*Correspondence: enisa.mede@gmail.com
} 
learner may produce a perfectly grammatical utterance that the listener can understand, but he or she may not know how to convey the social meaning communicated in the target context. The inconsistency between the language teaching methodologies and the specific needs for language use in the real world has become more distinctive than ever. Kramsch (2014) highlights this tension:

"...there has never been a greater tension between what is taught in the classroom and what the students will need in the real world once they have left the classroom. In the last decades, that world has changed to such an extent that language teachers are no longer sure of what they are supposed to teach nor what real world situations they are supposed to prepare their students for."

The lack of promoting sociolinguistic competence in foreign language learners becomes more evident when they start to use English for actual communication in real life as is also stressed by Kramsch. In the past, students used to learn English as part of curriculum and mainly for passing the tests to be able to graduate. However, today most of them need to learn another language for using it actively as a result of increasing needs. This changing need should be carefully analyzed and integrated into the curriculum and classroom practices through the teachers who serve as the agent of change and development. Kramsch (2014) also connects the lack of skills to use language in the real worlds to the expectations from the teachers, who are supposed to teach and carry students to a particular level of proficiency. She implies that classroom teaching practices are controlled by the impositions at macro level decisions. They are also supposed to cover the language teaching materials in line with the curricula and syllabuses provided for them to follow.

It is evident that teaching how to use language in classroom setting is not a simple task that could be changed readily. Learning a second/foreign language is a holistic process that requires not just the mastery of structural, discoursal, and strategic rules but also, learners have to internalize sociolinguistic rules to assist them in the choice of appropriate forms ( $\mathrm{Yu}$, 2006). This study, therefore, aims to highlight these issues by investigating native and nonnative English teachers' perceptions of the knowledge and practice of sociolinguistic competence as part of communicative competence in language classrooms. Based on the data obtained thorough a questionnaire and written reports, the present research examines and discusses the crucial points English teachers should be aware of while teaching this particular competence in their classroom.

\section{Literature Review}

\section{Communicative Competence}

The term "competence" is derived from the concept of "performance" firstly proposed by Chomsky in the 1960s. The former is the linguistic knowledge of the idealized native speaker, an innate biological function of the mind that allows the speaker to generate the indefinite set of grammatical sentences that constitutes the target language whilst the latter is the actual use of language in concrete situations. However, according to Campbell and Wales (1970), Chomsky's competence omitted the linguistic ability referring to the production or use of utterances which are grammatically incorrect, but appropriate to the context or the situational and verbal context of the utterance. In a similar fashion, Hymes (1972) emphasized that in addition to the linguistic competence, the language user has another intuitive system in which the rules of grammar would be useless. That is, he or she can adjust his or her language 
use based on the factors as the topic, situation and human relations. Based on his argument, he proposes the concept of "communicative competence" which includes both linguistic competence and implicit and explicit knowledge, both the rules of grammar and contextual or sociolinguistic knowledge of the rules of language use in contexts. To put it simply, Hymes states that communicative competence involves the following: what is formally possible, what is feasible, what is the social meaning or value of a given utterance, and what actually occurs.

After Hymes, the concept of communicative competence continued to develop. Canale and Swain (1980) defined communicative competence in the context of second language teaching as a synthesis of knowledge of basic grammatical principles, knowledge of how language is used in social settings to perform communicative functions, and knowledge of how utterances and communicative functions can be combined according to the principles of discourse. Based on their view, communicative competence comprises four areas of knowledge and skills. These are grammatical competence (also called linguistic competence) or the acquisition of phonological, morphological, syntactic and semantic rules. In other words, it is the mastery of the language code itself. The next one is the sociolinguistic competence which refers to the learning of pragmatic aspects of various speech acts such as the cultural values, norms and other socio-cultural conventions in social contexts. Specifically, the styles and registers of speech are influenced by the topic of discourse, the social status, gender and age of the participants. Another area of knowledge of rules is the discourse competence which stresses the importance of the mastery of how to combine grammatical forms and meanings to achieve unified written text in different genres such as narratives, argumentative essays, academic papers etc. Basically, this type of competence is related to the cohesion (grammatical links) and coherence (appropriate combination of communicative functions) in a variety of discourse. Finally, strategic competence is the mastery of verbal and nonverbal communication strategies to compensate for communication breakdowns (e.g. activating background knowledge, contextual guessing etc.) due to limiting conditions or insufficient competence and to enhance the effectiveness of communication.

The specific ability to use L2 in various ways that may fit in various social settings in which the communication takes place is called sociolinguistic competence, and without this ability, even the most perfectly grammatical utterances can convey a meaning entirely different from what the speaker intended because there are several factors that are to be considered when communicating in L2 such as age, gender, status of the participants and the formality of the setting. Specifically, sociolinguistic competence can be generally divided into two areas. One is appropriateness of form, that is, pragma-linguistics, which signals "the particular resources that a given language provides for conveying particular illocutions" (Leech, 1983, p. 11); the other is appropriateness of meaning, that is, socio-pragmatics, which defines the ways in which pragmatic performance is subject to specific sociocultural conventions and values (Kasper \& Blum-Kulka, 1993). For non-native speakers, the misunderstandings they come across in the cross-cultural realization of communicative acts generally arise from their failure in appropriate use of pragma-linguistic and socio-pragmatic competence (Yu, 2006).

In addition, Ya (2008) argues that one of the factors that make sociolinguistic competence so hard to acquire is the variance in cultural rules of speaking as well as the social, cultural and pragmatic elements that inherently exist in that competence. To put it differently, what is appropriate in one cultural situation might be entirely inappropriate in another one. The language learner often cannot differentiate between the rules of speaking of his or her native context and those of the target context. 
These rules of speaking can be gradually acquired when the learner is immersed in the target culture. This is a time consuming process though. As for the second or foreign language context, raising learners' awareness about the rules of speaking might help them acquire these skills more efficiently and in less time (Mizne, 1997).

It is clear that sociolinguistic competence is a multifaceted and multi-layered one that requires knowing how speakers of a language use it to communicate in a way that will not bother one another. Such social, cultural and pragmatic aspects would be hard to acquire without being integrated into the culture, however, it is not impossible. Access to books, listening materials, videos and any materials that reflect the culture of the target language community is available. There are also more opportunities available that enable people from different cultures and countries to come together whether face-to-face or online. However, how these resources are brought together and how they are implemented and made use of by language teachers in the classrooms are the key issues in the teaching of sociolinguistic competence. This leads to the question of how second or foreign language teachers can develop the sociolinguistic competence of their learners? As Mizne (ibid.) discusses, one of the problematic areas about this issue is that both culture and sociolinguistic features are difficult to teach particularly when the learners are not yet competent in the second or foreign language. Another problem is that these cultural and sociolinguistic aspects of a language are unconsciously ingrained within the learner, which makes it hard for the teachers to integrate them in the language classrooms. Finally, the cultural elements of a language are generally introduced as an add-on topic through textbooks or supplementary materials, while sociolinguistic features are left for the language learner to learn on his or her own through experience (Mizne, ibid.). In other words, there are not enough materials designed and developed to introduce the cultural and the sociolinguistic aspects of the target language in classrooms. Even if there are, the human resources who should use them in the classroom seem to be lacking. The present study will also elaborate this factor on the basis of the data collected from teachers themselves.

Based on the discussion above, it is obvious that Canale and Swain's (1980) framework attempts to highlight the kinds of knowledge and skills that a second language learner needs to be taught. From this perspective, the development of the theoretical basis for a communicative approach in the second language teaching will depend on an understanding of the nature of human communication.

\section{Teaching Sociolinguistic Competence}

There are two basic ways of introducing and teaching sociolinguistic competence. One of them is resorting to cultural models where students are explicitly or implicitly taught cultural elements ingrained in language use and/or integrating speech acts as situations where learners are forced to use language in consideration of socio-pragmatic factors such as social statues of the hearer, the degree of imposition, or the content of the request. Classroom environment may not be an appropriate context where sociolinguistic competence can be developed due to several reasons unique to any learning experience in an EFL context such as non-authenticity of the content of the materials. For example, Izumi (1996) highlights that in developing sociolinguistic knowledge, most non-native speakers (NNS) who teach English experience challenges such as their own lack of knowledge, the existing curriculum requirements, the various teaching goals, student motivation, and evaluation procedures. These factors play a critical role in the process of learning how to use language in an appropriate way because the major concentration of most EFL learners is devoted to learning what the rules of language are and how they can produce grammatical sentences rather than 
how they can produce appropriate sentences that fit the specific social context. For example, whatever the proficiency level of EFL learners is, there is usually room for development in their socio-pragmatic use of language because Bardovi and Harlig (1996) claim that proficiency does not improve concomitantly with the ability to use foreign language appropriately by operationalizing their sociolinguistic competence. Izumi (1996) concludes that for all the challenges in learning and teaching of sociolinguistic competence, it is possible to help students to promote and acquire this competence by raising their awareness in the rules of sociolinguistic use of language as argued by Ellis (1991).

Omaggio (2001) highlights three main reasons why sociolinguistic competence is not often treated as a topic in its own right and as an indispensable aspect of language teaching: a) Language teachers often think that they do not have time for sociocultural teaching due to time constraints in their curriculum. b) Teachers may not have enough confidence in believing that they can teach sociocultural aspect of foreign language learning well. c) The teaching of sociocultural competence often involves dealing with student attitudes which teachers usually find very challenging when trying to guide their students to understand and appreciate the logic and meaning of the target culture.

Similarly, Ya (2008) reports lack of context where students use language communicatively, but suggests that as most of foreign language learning occurs in the classroom setting, providing opportunities to use authentic and natural language seems to be difficult to achieve. Ya (ibid.) discusses several sources which impede learning and teaching of sociolinguistic competence. Among them is transfer from L1, which involves transferring of L1 sociocultural patterns into the L2 sociolinguistic rules of language use, often due to the limited knowledge of sociolinguistic competence of L2. One of the reasons for such limitation is that, as Holmes and Brown (1987) argue, explicit teaching of discrete grammatical rules, segmental level of pronunciation, and lexical items seem easier, during which sociocultural aspects of communicative competence are thought to be incidentally acquired. However, this is a problematic claim because knowing rules of language along with how to pronounce individual words and what they mean may not necessarily ensure knowing the sociolinguistics contexts in which they might be used. The knowledge about sociolinguistic values of linguistic forms is constructed on the basis of the social context and cultural environments where language is naturally used. The functions and socio-pragmatic values of forms are attached to them in actual communication. From a pedagogical perspective, the situation seems complex for the teachers who are expected to help students promote communicative competence in the classroom setting, which can be developed by close interaction with native speakers. This also leads to a critical debate which is devoted to the teachers' own sociolinguistic competence because to be able to effectively teach sociolinguistic competence, teachers need to have knowledge and practice of this competence to an extent that they can help students develop it. However, having come from the same educational system which lacked proper instruction on improving learners' sociolinguistic competence, most teachers either neglect teaching what they themselves feel weak or teach this competence with an ineffective mode of instruction. This issue of teachers' owns lack of sociolinguistic competence needs to be addressed adequately. This can only be achieved with a proper planning of teaching this competence to teachers or offering them opportunities where they interact with native speakers of English to foster a critical understanding of English culture and relevant language use. The reported problems can also be achieved by changing the curriculum and syllabuses followed in a way that supports the teaching of this competence. The findings from qualitative data will also address the factors that are claimed to pose challenges to the development of sociolinguistic competence in learners. 


\section{Communicative Competence in Curriculum Planning, Syllabus Design, Integration and Material Development}

In order to have a valid and affective outcome of foreign/second language teaching process, the macro and micro policies with special attention to curriculum planning, syllabus design and integration and presentation plans should be closely taken into consideration. A language curriculum is an overall language program which includes teaching objectives, specification of contents, learning activities that aim to achieve the objectives, ways to measure learning achievements, and evaluation of each aspect of the curriculum.

Understanding the concept of communicative competence and applying it is a challenging process, particularly in terms of its adaptation and implementation in second/foreign language teaching and learning curricula. Regarding the adoption of the communicative competence in developing such language programs, a transition from the proposed syllabus combining the structurally-based approach to the communicative based language teaching is needed. Kern (1990) refers to this type of syllabus as 'competency-task based syllabus' in which language learners' competencies are required for the course as well as competencies to be developed during the course are outlined, explained and resulted in increased student performance. Competency-based objectives specify what the learners will be able to do with the English language they have learned. In order to achieve those objectives, the methodology which underlines such competencies should be identified in the syllabus. In brief, the needs of the learners, classroom activities, teacher roles and teaching materials should be thoroughly designed.

\section{Method}

In the light of the literature review presented in the previous section, development of the communicative competence in second/foreign language learners is a vital skill which should be closely integrated in language teaching and learning curricula based on competencies and tasks that focus on meaning, have a goal, emphasize the outcome and reveal a real world relationship by using the definitions and the criteria specified above. However, before the unification of the communicative competence in the language curriculum, the learners' level of such competences should be determined. Within the scope of this study, the focus is primarily on the English teachers' perceptions about their own and their learners' level of one part of communicative competence namely, sociolinguistic competence which is often neglected in the second/foreign language curricula. Specifically, the study attempts to find out the perceptions of the EFL teachers with regard to the knowledge of learners' sociolinguistic competence, the perceptions of the non-native EFL teachers about their own knowledge of sociolinguistic competence and the difficulty they face with the integration of this particular competence in their classrooms, the possible sources in helping learners develop sociolinguistic competence and the perceptions of the native EFL teachers about the effective ways of developing non-native teachers' own and their learners' sociolinguistic competence. The following research questions were addressed:

(1) What are the perceptions of the EFL teachers with regard to non-native teachers' and learners' knowledge of sociolinguistic competence?

(2) What kind of difficulties do the EFL teachers experience with the development of learners' sociolinguistic competence?

(3) What are the perceptions of the non-native EFL teachers about their own knowledge of sociolinguistic competence and the difficulty they experience with the integration of this particular skill in their classroom? 
(4) What are the EFL teachers' perceptions about the possible sources in helping learners develop sociolinguistic competence?

(5) What are the perceptions of the native EFL teachers about the effective strategies of developing non-native teachers' own and their learners' sociolinguistic competence?

\section{Participants}

Seventy EFL teachers (35 natives and 35 non-natives) participated in the study. All of the participating teachers were instructors in the English preparatory programs of various universities across Turkey. Findings of the background questionnaire indicated that the EFL teachers, both native and non-native, had at least six years of teaching experience. All of the participating teachers had visited at least one foreign country.

\section{Data Collection Procedure}

In accordance with the aims of the study, data came from two sources: (a) a questionnaire to find out the perceptions of the EFL teachers with regard to the non-native teachers' own and their learners' sociolinguistic competence, and (b) written reports to investigate the participating teachers' perceptions about the knowledge of learners' sociolinguistic competence, the perceptions of the non-native EFL teachers about their own knowledge of sociolinguistic competence and the difficulty they face with the integration of this particular competence in their classrooms, the possible sources in helping learners develop sociolinguistic competence and the perceptions of the native EFL teachers about the effective strategies of developing non-native teachers' own and their learners' sociolinguistic competence.

The questionnaire administered in this study comprised three sections. The first section attempted to investigate the EFL teachers' perceptions (both native and non-native) about learners' knowledge of sociolinguistic competence whilst the second section emphasized on the non-native EFL teachers' perceptions about their own knowledge with respect to sociolinguistic competence. The questionnaire was adopted from the Common European Framework of Reference (2001), which aims to standardize language syllabuses, curriculum guidelines, examinations, textbooks, etc. Specifically, it is used across Europe by explicitly describing objectives, content and methods. Finally, the last section of the questionnaire aimed to gather some personal data from the participants.

Furthermore, to support the quantitative data gathered from the questionnaire, semi-structured interviews were conducted with 40 (20 native and 20 non-native) randomly selected EFL teachers. Specifically, the aim of the interview was to find out the EFL teachers' perceptions about the knowledge of learners' sociolinguistic competence, the perceptions of the nonnative EFL teachers about their own knowledge of sociolinguistic competence and the difficulty they face with the integration of this particular competence in their classrooms, the possible sources in helping learners develop this skill and the effective ways of developing non-native EFL teachers' own and their learners' knowledge of sociolinguistic competence.

\section{Data Analysis}

Descriptive statistics (mean and standard deviation) was used for the analysis of the questionnaire data. The analysis of the open-ended questions and the transcribed interview data was done through content analysis (Strauss and Corbin, 1990). The analysis process began with the open coding of the data followed by inducing categories from these codes, 
which were then gathered under general themes for each set of data relating to specific questions. The categories and themes were subject to the checking of inter-raters. To achieve the degree of inter-rater reliability, one native and one non-native speaker who are experts in ELT as well as one of the researchers in this study identified themes from the codes. It emerged that the raters achieved close agreement on the general themes apart from the different verbalizations of similar concepts.

\section{Results}

\section{The Perceptions of the EFL Teachers about the Knowledge of Learners' and Non- Native Teachers' Sociolinguistic Competence}

In an attempt to find out the perceptions about the EFL teachers (both native and nonnative) with regard to the learners' knowledge of sociolinguistic competence (SC), both groups stated that the students could only perform and respond to basic language functions (e.g. invitations, suggestions, apologies etc.), use simple common expressions (e.g. greetings, farewells, introductions etc.) and follow basic routines (see Table 1).

Table 1: The EFL Teachers' Perceptions about Learners' Knowledge of SC

\begin{tabular}{lllll}
\hline & Natives & \multicolumn{3}{l}{ Non-natives } \\
Proficiency level & M & SD & M & SD \\
\hline C2 & 2.22 & 0.64 & 2.48 & 0.70 \\
C1 & 2.34 & 0.72 & 2.45 & 0.85 \\
B2 & 2.57 & 0.88 & 2.51 & 0.74 \\
B1 & 2.37 & 0.84 & 2.82 & 0.78 \\
A2 & 3.40 & 0.81 & 3.37 & 0.87 \\
A1 & 3.48 & 0.81 & 3.48 & 0.88 \\
\hline
\end{tabular}

It is clear from the mean scores reported in the above table that the level of sociolinguistic competence decreases as learners' proficiency increases. EFL teachers' perceptions of the success level of each group of learners indicate a serious problem. One would normally expect that learners should develop sociolinguistic competence as they become more proficient.

Furthermore, to support the findings gathered from the questionnaire, the following figure shows the distribution of responses regarding how native and non-native EFL teachers perceive the development of the sociolinguistic competence in learners. To begin with, the native EFL teachers perceive this issue as a critical problem both in non-native EFL teachers and learners. They also stress that the relatively low level of sociolinguistic competence in non-native EFL teachers might lead them to experiencing difficulty in the application of this particular competence in their own classrooms.

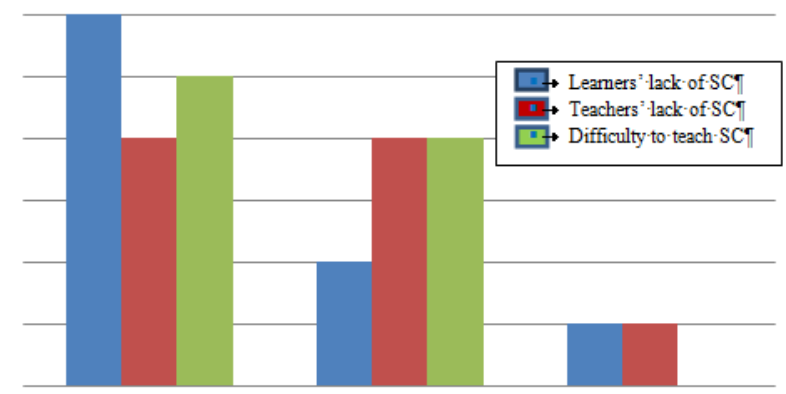

Figure 1: The Native EFL Teachers' Perceptions about SC in Non-native Teachers and Learners 
Similarly, the following figure shows the distribution of responses regarding how non-native EFL teachers perceive the development of the sociolinguistic competence in themselves and their learners. It can be seen that the non-native teachers indicate low acquisition of this competence by themselves and learners. It is also reported that the relatively low level of sociolinguistic competence in them might contribute to experiencing difficulty with the development of this competence in language learners.

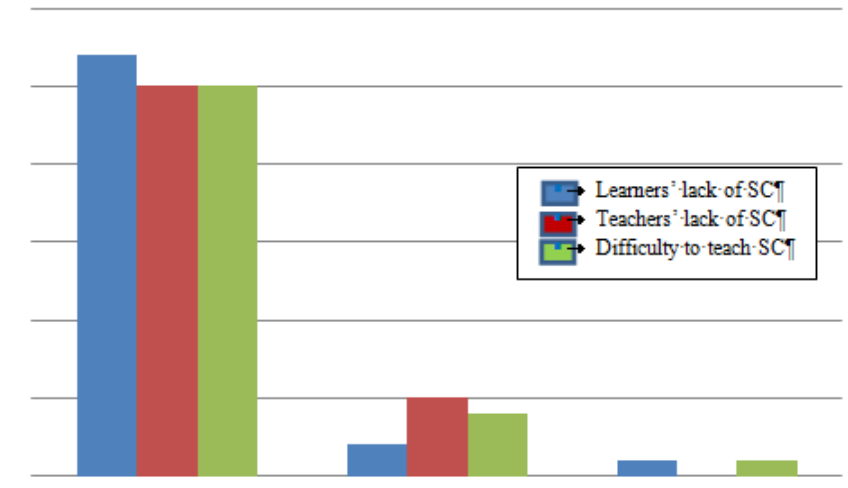

Figure 2: The Non-native EFL Teachers' Perceptions about the knowledge of SC in themselves and their Learners

Based on the data shown in the figures above, there is a correlation showing that learners' lack of knowledge can be linked to teachers' own lack of sociolinguistic competence. One possible reason behind this finding might be due to the fact that non-native EFL teachers avoid integrating this particular competence in their classrooms due to their own lack of knowledge and thus, feeling uncomfortable. In other words, they might not focus on what they don't know and avoid teaching the topic.

\section{The Difficulty the EFL Teachers Experience with the Development of Learners' Sociolinguistic Competence}

Regarding the difficulty the language learners face with the development of the sociolinguistic competence, the EFL teachers reported specific causes for the low level of this particular competence. What follows is a comprehensive account of their responses.

Table 2: Possible Causes of Learners' Failing to Develop SC in Language Classrooms

\begin{tabular}{ll}
\hline Central themes & Sub-themes \\
\hline Pedagogical Issues & $\begin{array}{l}\text { Lack of sufficient interaction with natives } \\
\text { Lack of exposure to culture } \\
\text { Formal learning principles }\end{array}$ \\
& $\begin{array}{l}\text { Learning objectives } \\
\text { Instrumental motivation to learn } \\
\text { Test-dependency through goals } \\
\text { SC not tested in the exams }\end{array}$ \\
& Curricular content lacks SC \\
& Teacher and learner perception \\
Personal and Contextual Constraints & Teachers' and students' attitudes \\
\hline
\end{tabular}


Parallel to the survey findings, the participants provided detailed and insightful responses during the semi-structured interviews with regard to the difficulty the EFL teachers experience with the development of learners' sociolinguistic competence, which were then sub-thematised into four ways.

\section{Pedagogical Issues}

Students are solely learning in a classroom environment and in a test based system. The amount of effort to keep up with the books kills any energy needed to socially interact with the language be it through conversation or watching TV (Native EFL teacher 1).

Learners usually fail to develop this type of competence as they are the members of an education environment in which they need to focus on theoretical aspects of almost anything, rather than practice; that is, they highly focus on mechanical facets such as grammar, vocabulary and the like. Still, some students have promising attitude towards sociolinguistic perspective (Non-native EFL teacher 1).

\section{Assessment}

Learners have been conditioned by the test centric systems (Native EFL teacher 3).

At school, students concentrate on written grammar and vocabulary in order to pass exams (Native EFL teacher 4).

In general, language studies are not done for communicative purposes; it is most usually done for the exams. Materials are generally designed for the same purpose (Non-native EFL teacher 3).

\section{Curriculum}

It often has not formed part of the curriculum through which they learned the language and depends on their own cultural attachment to the target language and how integrated they want to become in that culture (Native EFL teacher 2).

Neither the curriculum nor the course materials applied in schools enable our students to develop this competence (Non-native EFL teacher 2).

\section{Personal and Contextual Constraints}

Sometimes students don't always put in the effort (Non-native EFL teacher 4).

.... I guess it is just a matter of interest, effort and time (Non-native EFL teacher 5).

..It needs time, some effort, and will (Non-native EFL teacher 6).

The amount of effort to keep up with the books kills any energy needed to socially interact with the language be it through conversation or watching TV. (Native EFL teacher 5). 
Based on the gathered data, both native and non-native EFL teachers relate the learners' failure to four major constructs including pedagogical characteristics, curriculum and assessment issues, and personal and contextual constraints. The major cause is seen as pedagogical characterizing the context of learning where learners have little chance of interacting with native people in natural settings. Another is the curriculum and assessment issues, showing that top-down decisions for how language will be taught and assessed influences student learning. The other is personal causes, involving teachers and learners. The former is criticized for not properly understanding the role of sociolinguistic competence, where the latter is criticized for not putting adequate amount of effort into promoting their sociolinguistic competence. All these factors emerging from native teachers' responses seem to play a critical role in developing sociolinguistic competence.

\section{The Perceptions of the Non-Native EFL Teachers'Sociolinguistic Competence}

According to the data obtained from the questionnaire, the non-native EFL teachers argued they lacked their own knowledge of sociolinguistic competence (SC) considering different proficiency levels in CEFR as shown in Table 3 below.

Table 3: The Non-native EFL Teachers' Perceptions about their Own Knowledge of SC

\begin{tabular}{lll}
\hline Proficiency level & M & SD \\
\hline C2 & 2.00 & 0.84 \\
C1 & 2.14 & 0.87 \\
B2 & 2.31 & 0.83 \\
B1 & 3.08 & 0.81 \\
A2 & 3.08 & 1.03 \\
A1 & 3.92 & 1.67 \\
\hline
\end{tabular}

As shown in the above results, the non-native EFL teachers self-assessed themselves as not having the sufficient knowledge related to sociolinguistic competence. To put it other way, they could perform and respond to basic language functions, use simple common expressions and establish basic social contact.

With regard to the non-native EFL teachers' self-assessment on their level of sociolinguistic competence, the same group of participants had diverse range of responses to the question of why non-native teachers have difficulty in integrating sociolinguistic competence in their classroom context. The central themes include lack of awareness, lack of exposure to the target culture, teacher beliefs, and the curriculum.

Table 4: Perceptions about the Difficulty of Integrating SC by the Non-native EFL Teachers

\begin{tabular}{ll}
\hline Central themes & Sub-themes \\
\hline Awareness & $\begin{array}{l}\text { Lack of teachers' awareness in SC } \\
\text { Lack of recognition of the need }\end{array}$ \\
Exposure & Lack of exposure to the target culture \\
Teachers' beliefs & $\begin{array}{l}\text { Deeply seated social beliefs } \\
\text { Teachers' preferences of language teaching }\end{array}$ \\
Curriculum & No curriculum integration \\
\hline
\end{tabular}


In addition to the results illustrated in the above sections, similar perceptions were highlighted by the two groups of participating teachers with regard to the difficulty the non-native EFL teacher had while trying to teach sociolinguistic competence in their classrooms. The following excerpts clarifying this point were categorized under four themes namely, lack of teacher awareness, and lack of exposure to the target culture, teachers' beliefs and the curriculum.

\section{Lack of Awareness}

Perhaps due to a lack of awareness, and non-native EFL teachers don't see the need. (Native EFL teacher 6).

... non-native EFL teachers are unaware of its importance and have probably received very little if any training on how to integrate these skills into a general English proficiency course (Native EFL teacher 7).

I don't even think our teachers are aware of any dimensions composing any language we teach (Non-native EFL teacher 7).

....our teachers are not well aware of the components of the target culture (Non-native EFL teacher 8).

\section{Lack of Exposure to the Target Culture}

....their experience with native/non-Turkish speakers of English or of travelling abroad is limited, so they do not have many opportunities to observe or practice this competence (Native EFL teacher 8).

If the teacher is not a native speaker, or has not lived in a native speaking country for some time, I believe that it would be difficult to know how to convey this (Native EFL teacher 9).

Many teachers in Turkey lack this competence due to dominance of theoretical approaches other than practical discourse and cultural studies in their education and lack of opportunity given in terms of having sufficient experience of interaction with native speakers (Non-native EFL teacher 9).

If the teacher has never spent an extended amount of time in an English speaking country, or in the company of native English speakers, it can be difficult to truly develop this competence (Non-native EFL teacher 10).

\section{Teachers'Beliefs}

If they are well-informed and believe it is important to develop learners' sociolinguistic competence, then it should be possible for them to at least raise learners' awareness ... (Native EFL teacher 10).

It isn't always easy develop the competence as they already have a set of social beliefs etc. in their heads (Native EFL teacher 11).

If the teacher feels/knows the importance of sociolinguistic skills, students just acquire it from the teacher(s) easily (Non-native EFL teacher 11). 
Even if the teacher herself tries to introduce such concepts as politeness and impoliteness forms they do not take them seriously. In their eyes, these are "unnecessary stuff" or "there is no need to be too polite" (Non-native EFL teacher 12).

\section{The Curriculum}

.... it often has not formed part of the curriculum through which they learned the language and depends on their own cultural attachment to the target language and how integrated they want to become in that culture (Native EFL teacher 12).

... it would also be desirable for curricula to be less exam oriented and more conducive to developing communicative skills (Native EFL teacher 13).

Neither the curriculum nor the course materials applied in schools enable our students to develop this competence (Non-native EFL teacher 13).

I do not believe that these competences are taken into consideration sufficiently while developing curriculum (Non-native EFL teacher 14).

EFL teachers' responses with regard to their own knowledge of sociolinguistic competence resemble those of learners. The low level of descriptions for sociolinguistic competence seems to be posited, while relatively more complex ones are regarded to be less acquired. The reasons for underscoring of their own sociolinguistic competence are linked to four major constructs. One of the most critical is the confession that they lack knowledge, which can then be connected to lack of exposure and lack of need to teach them as it is not integrated in the curricula followed. All three can in turn be keys to formation of teacher beliefs about the relatively less important statues of this competence.

\section{The EFL Teachers' Perceptions about the Students' Difficulties in Sociolinguistic Competence}

When the participating EFL teachers were asked about their perceptions with regard to the sources of difficulties in helping learners develop sociolinguistic competence, both native and non-native teachers came up with the following themes:

Table 5: Sources of Difficulties in Helping Learners Develop SC

\begin{tabular}{ll}
\hline Central themes & Sub-themes \\
\hline Teachers' own competence & $\begin{array}{l}\text { Teachers' lack of awareness } \\
\text { Teachers' lack of competence } \\
\text { Teachers' lack of knowledge }\end{array}$ \\
& $\begin{array}{l}\text { Need for communicative-oriented syllabus } \\
\text { Curriculum dependency } \\
\text { Nurriculum and Syllabus }\end{array}$ \\
& Need for Communicative curriculum \\
Testing and Assessment & Focus on summative assessment \\
& Students reluctance \\
Students' own capacity & Limited language use \\
& Less time on speaking skills
\end{tabular}


In the same direction to the themes identified above, the two groups of teachers made the following comments with regard to the sources of difficulties in helping learners develop sociolinguistic competence.

\section{Teachers' Own Competence}

This will depend on their own competence and awareness of sociolinguistic issues, as well as their perception of the significance of teaching about these topics (Native EFL teacher 14).

....their competence may well be similar to that of learners, especially if they are not aware of the relevance of this (Native EFL teacher 15).

As they themselves have difficulty in developing their own sociolinguistic competence, teachers usually have difficulty in helping learners develop stated competence (Non-native EFL teacher 15).

It is also very challenging to achieve this when even we (teachers) are not completely competent in terms of these skills (Non-native EFL teacher 16).

\section{Curriculum and Assessment}

The teachers need a new curriculum which includes this competence and new materials to be applied during the lessons and required time to make students gain this competence (Non-native EFL teacher 17).

I guess it is due to the artificial language of course books and the objectives of the language teaching institution (Non-native EFL teacher 18).

...there is a strict curriculum teachers need to follow, and this competence is not much given attention unfortunately (Native EFL teacher 16).

If it was considered more desirable to be able to communicate with a native speaker than to pass exams, then teachers would be able to, indeed, be required to concentrate on teaching the learners communication skills, including sociolinguistic appropriateness (Native EFL teacher 17).

\section{Student-Related Factors}

Students tend to focus on other aspects of learning the language such as exams and quizzes (Non-native EFL teacher 19).

Our students are usually only concerned with passing a test so that they may continue to study their department (Native EFL teacher 18).

As shown in the gathered data, the two groups of EFL teachers report several reasons about why they have difficulty in helping learners develop sociolinguistic competence. These reasons are related to several key issues in language teaching such as teachers' characteristics and teaching skills, curriculum and assessment, and student-related factors. The emerging data show a clear link between teachers' own competence in teaching sociolinguistic competence and the top-down language teaching policies involving summative testing and curricular characteristics of syllabuses imposed for implementation. 


\section{The Native EFL Teachers' Perceptions about the Effective Ways of Developing Sociolinguistic Competence}

As for the effective ways of developing non-native EFL teachers' and learners' sociolinguistic competence, the native teachers made the suggestions highlighted below.

Table 6: Native EFL Teachers' Suggestions for Development of Non-native Teachers' and

\begin{tabular}{ll} 
& Learners'SC \\
\hline Central themes & Sub-themes \\
\hline Acquisition & $\begin{array}{l}\text { Interaction with natives } \\
\text { Increased cultural exposure }\end{array}$ \\
& $\begin{array}{l}\text { Functional practices } \\
\text { Teaching/learning }\end{array}$ \\
& $\begin{array}{l}\text { Promoting exposure through media } \\
\text { Prioritizing SC } \\
\text { Selecting authentic materials }\end{array}$
\end{tabular}

To support this issue, the following two themes were grounded from the data collected from the semi-structured interviews conducted with the native and non-native EFL teachers.

\section{Acquisition}

It would be beneficial for non-native speakers to make more of an effort to interact with native speakers (Native EFL teacher 19).

They need more opportunities to interact with the target community and native speakers (Native EFL teacher 20).

By integrating the foreign language into their lives and using it in authentic situations where it becomes a medium rather than an end in itself (Non-native EFL teacher 20).

With the use of technology, the internet, using authentic materials and language, joining and encouraging students to join language programs and projects, creating opportunities to talk to and being in the same environment with native speakers of the language (Non-native EFL teacher 21).

\section{Teaching/Learning}

It can be developed by principled, practical teaching of social aspect of language (Native EFL teacher 21).

Being aware of the importance of learning, and then teaching the social competence in a language would be the first step towards success (Native EFL teacher 22).

...teachers can help students by providing activities and real life examples in the language being taught (Non-native EFL teacher 22).

As summarized above, the responses regarding how teacher can help learners promote sociolinguistic competence can be divided into three central themes. One is need for learning context, highlighting the need for exposure to acquiring language. Native EFL teachers' perceptions about foreign language learning imply learners should also be exposed to natural 
setting where they can interact with native people free from being imposed on with summative assessment practices. Another central theme is need for a strong focus on explicit teaching of the basic elements of sociolinguistic competence in formal context. The other major theme is the need for teachers to be further trained to promote how to teach sociolinguistic competence. This theme implies a criticism over foreign language teachers' own competence made explicitly by native teachers who are working in Turkey. It is clear that many native teachers make critical connections between foreign language teachers and their abilities to teach sociolinguistic competence by stressing the need for further education. The critical issue here is the integration of media into curriculum to provide authentic input for students to promote their sociolinguistic competence (relevant to input based learning hypothesis). Another important emerging idea on the basis of their responses is that there should be integration formal teaching practices into a setting where students can be exposed to authentic, natural language use. Finally, the curriculum is another crucial issue obtained from the data. It is though that top-down decisions to include syllabuses also aiming for sociolinguistic competence can help teachers and learners promote this competence.

\section{Discussion}

The current study attempted to investigate the perceptions of the English teachers with regard to the knowledge and practice of sociolinguistic competence in language classrooms. Specifically, the perceptions of the non-native EFL teachers about their own knowledge of sociolinguistic competence and the possible difficulties they may face with the integration of this particular competence in their classrooms. Besides, the effective ways in helping learners and non-native English teachers' develop sociolinguistic competence and integrate this vital skill in language classrooms were also examined.

The analyses of the surveys and written reports revealed low level of descriptions for learners' knowledge with respect to sociolinguistic competence. The EFL teachers stated that learners only felt comfortable with performing and responding to simple language functions. One of the most critical point behind this finding is the confession that the non-native teachers themselves lack this particular knowledge, which can then be connected to teacher beliefs, lack of exposure to the target culture and lack of need to teach it as it is not integrated in the existing curricula assessment. To put it simply, similar to Izumi's (1996) findings, since nonnative EFL teachers did not feel comfortable with the integration of this particular strategy due to their lack of knowledge, lack of exposure and lack of need to teach it, they avoided emphasizing its development in their learners.

In addition, another important finding related to the difficulty the EFL teachers experienced with the development of their learners' sociolinguistic competence was similar to the previous section. One of the major causes of this failure was linked to pedagogical and personal issues. In other words, since the learners were learning English in a foreign language context, they had little opportunity to engage in authentic contexts with native speakers out of the classroom which is in parallel with Ya's (1998) study suggesting that as most of foreign language learning occurs in the classroom setting, providing opportunities to use authentic and natural language seems to be difficult to achieve.

Another two notable findings were related to assessment and curriculum which lacked the materials designed for the development of sociolinguistic competence. As previously mentioned, since sociolinguistic competence is closely related to the sociocultural side of language learning, the current finding in fact lends support to Omaggio's (2001) argument 
that the teaching of culture, remains insubstantial in most L2 classrooms, and, therefore, is one of the most often neglected aspects in foreign language curriculum and assessment.

Accordingly, an important finding of this study was that increased cultural exposure and interaction with native speakers are notable sources for helping learners' develop their knowledge of sociolinguistic competence. The learners should be exposed to authentic contexts where they could express themselves to the native speakers of the target language. Another effective way for the students' progress in this particular strategy was related to explicit teaching of the basic components of sociolinguistic competence which brings the need for teachers to receive training on how to adapt their instructional practices into a setting by raising the awareness of the learners about the rules of sociolinguistic use of language as suggested by Ellis (1991) and Holmes and Brown (1987). Finally, redesign of the existing curriculum and assessment in accordance with focus on the effective ways of improving sociolinguistic competence can help both teachers and learners promote this particular strategy.

\section{Conclusion and Suggestions}

The present study suggests that the development of the communicative competence in second/foreign language learners is a vital skill which should be closely integrated in language teaching and learning curricula. Therefore, both teachers' and learners' level of such competencies should be thoroughly identified to come up with more meaningful tasks that have a goal, emphasize the outcome and reveal a real world relationship. And in Turkey, where students are not exposed to the target culture, it is the responsibility of the EFL teachers to raise the awareness of the learners about the sociolinguistic use of the language through a variety of strategies.

The findings of this study have clear methodological recommendations for the development of the communicative competence in the foreign language teaching and learning curricula. First of all, in order to teach English communicatively, the teachers should be aware of the importance and functions of the sociolinguistic elements of language use. As for development of their own and learners' knowledge of sociolinguistic competence, language teachers should expose learners to authentic use of language and conversations through social media, songs, literature etc. and also design classroom practices engaging students to use the language in real-life contexts. Besides, students should be encouraged to interact with native speakers by joining the student exchange programs or the social network where they can make friends from different parts of the worlds. Finally, sociolinguistic norms of language use should be integrated in the existing curricula as well as in the assessment which will aid in with the development of this particular strategy both in teachers and learners. To conclude, as the present study was conducted in a Turkish EFL context, it is hoped that the gathered findings will serve basis for further development in the field of foreign language teaching and learning.

Finally, there are certain limitations in this study. First of all, an experimental study can be carried out to find out the effects of various classroom practices on learners' development of sociolinguistic competence. Next, oral data such as role plays can be gathered to provide more insights into the actual performances of the learners. In addition, other aspects of sociolinguistic competence such as phonological and lexical variations can be studied. Last but not least, more longitudinal studies on the development of sociolinguistic competence in English language teachers and learners can be carried out which will lead to more detailed and generalizable findings. It, therefore, can only be taken as suggestive of directions for 
future studies. Though much remains for future research, we feel that this study takes a step forward in terms of the development of the communicative competence in second/foreign language learners/teachers to be closely integrated in language teaching and learning curricula.

\section{References}

Bardovi-Harlig, K. (1996). Pragmatics and language teaching: bringing pragmatics and pedagogy together. In Bouton, L. F. (Ed).Pragmatics and Language Learning. Monograph Series, 7, 21-39.

Campbell, R., \& Wales, R. (1970). The study of language acquisition. New Horizons in Linguistics, 242-260.

Canale, M., and Swain, M. (1980). Theoretical bases of communicative approaches to second language teaching and testing. Applied Linguistics, 1(1), 1-47.

Ellis, R. (1991). Communicative competence and the Japanese learner. JALT Journal, 13(2), 103-129.

Holmes, J., and Brown, D. F. (1987). Teachers and students learning about compliments. TESOL Quarterly, 21(3), 523-546.

Hymes, D. (1972). On communicative competence. Sociolinguistics, 269293, 269-293.

Izumi, K. (1996). Teaching sociolinguistic knowledge in Japanese high schools. JALT Journal, 18(2), 327-340.

Kasper, G. \& Blum-Kulka, S. (1993). Interlanguage pragmatics. New York: Oxford University Press.

Kramsch, C. (2014), Teaching foreign languages in an era of globalization: Introduction. The Modern Language Journal, 98: 296-311.

Leech, G.N. (1983). Principles of pragmatics. New York: Longman.

Mizne, C. A. (1997). Teaching sociolinguistic competence in the ESL classroom. Senior Thesis Projects, 1993-2002. http://trace.tennessee.edu/utk_interstp2/20

Omaggio, A.C. (2001). Teaching languages in context: Proficiency-oriented instruction, 3rd ed. Boston, MA: Heinle \& Heinle Publishers.

Strauss, A., \& Corbin, J. M. (1990). Basics of qualitative research: grounded theory procedures and techniques. Sage Publications, Inc.

Ya, L. I. U. (2010). A study of language teaching from a sociolinguistic perspective of communicative competence. Canadian Social Science, 4(3), 80-86.

$\mathrm{Yu}$, M. C. (2006). On the teaching and learning of 12 sociolinguistic competence in classroom settings. Asian EFL Journal, 1-24. 